\section{Allergy \\ Immunology}

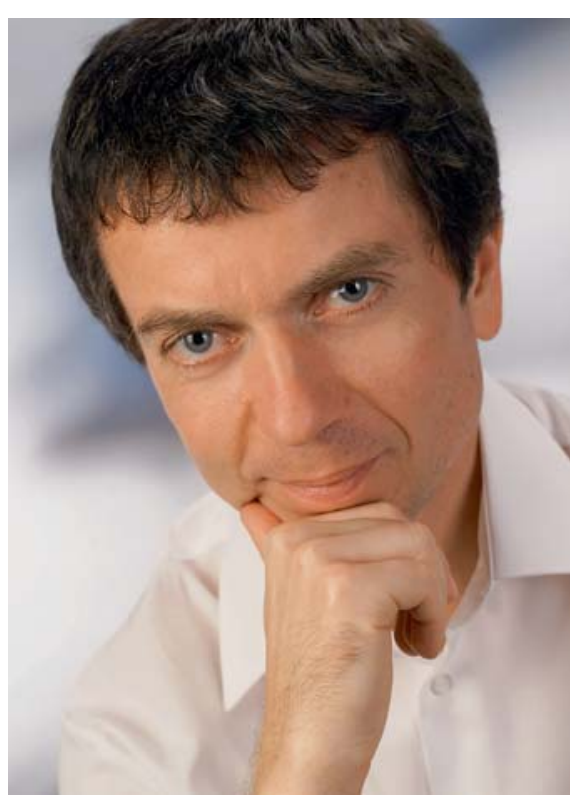

R. Valenta, Vienna.
Int Arch Allergy Immunol 2013;162:275

DOI: $10.1159 / 000355596$
Published online: October 17, 2013

\title{
Editor-in-Chief Rudolf Valenta
}

Rudolf Valenta studied medicine at the University of Vienna and earned his MD degree in 1987 with distinction. He then started to work on the molecular characterization of allergens, became Associate Professor at the University of Vienna and founded his research group 'Molecular Immunopathology' in 1993. Currently, Valenta holds a full professorship in allergology at the Medical University of Vienna. He coordinated two allergy research programs at the aforementioned university, served as Chairman of the Standardization Committee of the International Union of Immunological Societies (IUIS), as Vice President of the European Academy for Allergy and Clinical Immunology and as President of the Austrian Society for Allergology and Immunology. Furthermore, Rudolf Valenta is a member of the Austrian Academy of Sciences. He has been working in the field of allergy research for more than 25 years. Starting with the molecular and immunological characterization of important allergens, he continued to develop recombinant allergen-based diagnostic tests as well as therapeutic allergy vaccines based on recombinant allergens and genetically engineered hypoallergens and advanced them to clinical application. He has been awarded several prestigious national and international awards, among them the START Award of the Austrian Science Fund (FWF), the International Pharmacia Award and the Sarstedt Award, which he received in 2000 for his work on the genetic analysis of allergy-eliciting substances and their recombinant production (former awardees: Klose J, O'Farrell PH: Two-dimensional electrophoresis, 1986; Towbin H, Staehelin T, Gordon J: Western blot, 1988; Wilchek M, Bayer EA: Biotin-avidin system; Collins FS, Riordan J, Tsui L-C: Cystic fibrosis gene, 1993; Vogelstein B, Sidransky D: Molecular biology of malignant tumors, 1997). Rudolf Valenta's work is highly cited (cumulative citation index: >17.000; h-index: 69), and he has published more than 470 original scientific publications, reviews and book chapters. In addition, Valenta got more than 110 patents and introduced recombinant allergens into the diagnosis and treatment of allergic diseases. $\mathrm{He}$ is currently working on mechanisms of allergic diseases, the introduction of a new diagnostic, therapeutic and preventive concept for allergy into clinical use and the characterization of antigens in infectious diseases with the aim to develop diagnostic tests and vaccines in this area. 